Araştırma Makalesi - Research Article

\title{
Makine Seçimi Probleminin Entropi Ağırlıklı TOPSIS Yöntemi İle Değerlendirilmesi: Bir Doğal Taş İşletmesi Örneği
}

Geliş / Received: 25/04/2020

\author{
Gözde Koca ${ }^{*}$, Özüm Eğilmez²
}

Revize / Revised: 22/06/2020

Kabul / Accepted: 05/07/2020

\section{$\overline{\mathbf{o z}}$}

Sürekli yeniliğin simgesi olan teknolojik gelişimlerin bir sonucu olan ar-ge faaliyetleri makine tasarımına ve özelliklerine yansımaktadır. İşletmelerce önemli bir karar olan yeni teknoloji kullanımı bağlamında, bu çalışmada doğal taş(mermer) sektöründe faaliyet gösteren bir işletmede mermer işleme makinesi seçimi problemi fayda ve maliyet kriterleri göz önünde bulundurularak değerlendirilmiştir. Değerlendirme 14 farklı makine markası ve 5 farklı kriter (motor gücü, devir hızı, Z ekseni, maksimum testere çapı ve fiyat)bağlamında yapılmıştır. Kriterleri değerlendirmede Entropi yöntemi, alternatif makineleri değerlendirmede de TOPSIS yöntemi kullanılmıştır. Sonuçta yapılan objektif değerlendirmede en önemli kriterin "maksimum testere çapı (mm)" olduğu ve alternatif mermer işleme makineleri içinden en iyi alternatifin Alternatif 11 (A11) olduğu tespit edilmiştir. Kullanılan yöntemler ve elde edilen sonuçlar dâhilinde bu çalışma, uygulayıcıların sadece makine seçiminde değil, diğer tüm kaynak dağıtımı problemlerinde yararlanacakları bir referans olma özelliği taşımaktadır.

1*Sorumlu yazar iletişim: gozde.koca@bilecik.edu.tr (https://orcid.org/0000-0001-6847-6812)

Isșletme Bölümü, Bilecik Şeyh Edebali Üniversitesi, Bilecik, Türkiye

2İletişim:ozum.egilmez@bilecik.edu.tr (https://orcid.org/0000-0001-5251-5629)

İşletme Bölümü, Bilecik Şeyh Edebali Üniversitesi, Bilecik, Türkiye 


\title{
Evaluation of Machine Selection Problem by Entropy Weighted TOPSIS Method: An Example of A Natural Stone Company
}

\begin{abstract}
R\&D activities, which are the result of technological developments, the symbol of continuous innovation, reflect on machine design and features. In the context of the use of new technology, which is an important decision by the enterprises, the problem of choosing a marble processing machine in an enterprise operating in the natural stone (marble) sector was evaluated by considering the benefit and cost criteria. The evaluation was made in the context of 14 different machine brands and 5 different criteria (motor power, rotational speed, $\mathrm{Z}$ axis, maximum saw diameter, and price). Entropy method was used to evaluate the criteria, and TOPSIS method was used to evaluate alternative machines. In the final objective evaluation, it was determined that the most important criteria were "maximum saw diameter (mm)" and Alternative 11 (A11) was the best alternative among alternative marble processing machines. Within the methods used and the results obtained, this study is a reference that practitioners will benefit not only in machine selection but also in all other resource distribution problems.
\end{abstract}




\section{GİRIŞ}

Türkiye doğal taş (mermer ve granit sektörlerini kapsayan) sektöründe Çin ve İtalya ile birlikte öncü bir ülke konumundadır. Doğal taş sektörü, rezerv temelli olarak ihracat ağılıklı yaşamını sürdürmektedir. Bununla beraber, doğal taş kullanımının ihtiyaca bağlı olarak artması, sektörün canlılığını devamlı olarak sürdürebilmesini sağlamaktadır. Yeni çevre anlayışı ve sürdürebilirlik, doğal taş sektöründeki faaliyetleri de değiştirmektedir. Çeşitli işleme ve birleştirme teknikleri geliştirilerek ve hem çevreye verilen olası zararı azaltma, hem de rezervlerin işlerlik süresinin uzatılması yoluna gidilmiştir.

Gelişen yeni teknolojiler, öncelikle üretimde kullanılan makinelerde hem nitelik hem de nicelik anlamında gelişmelere neden olmuştur. Teknolojinin sunduğu yenilikler genel anlamda firsatlar barındırsa da, belirsizliğin bir yansıması olduğu için işletmelerde tehdit olarak görülebilmektedir. Hem stratejik yönetsel bakış hem de belirsizlik durumlarında en doğru kararı verebilmek adına, Çok Kriterli Karar Verme (ÇKKV) yaklaşımları tam da burada devreye girmektedir. Rekabet avantajını sürdürmek veya hızla büyüyen ve gelişen doğal taş sektöründe daha fazla yer almak adına, kimi zaman öncü, kimi zaman analizci ya da tepki gösterici strateji uygulamaları ile işletmeler bir takım faaliyetlerde bulunmaktadırlar. Seçilen strateji her ne olursa olsun, bir kararı ifade etmektedir. Karar vermede ise, alternatifleri doğru belirlemek ve doğru alternatifi seçmek önem arz etmektedir. ÇKKV yaklaşımları, karar vericileri çeşitli değişken ve parametreler karşısında çcözüm üretmeyi amaçlar. Karar vericileri, mevcut karar durumunu daha belirli bir yapı formunda hareket edebilecekleri nesnel bir bakış açısına sürükler. Bu şekilde, karar vericinin bir takım kişisel bilgi, tecrübe ve beceriye sahip olma zorunluluğu ortadan kalkmış olur. Bu sayede yönetsel kararlar daha merkezkaç bir yapı oluşturularak verilebilir. Karar verici yetkisine sahip her birey, ÇKKV yaklaşımları ile çoklu sayıda alternatifi bir arada değerlendirebilir. Böylesi bir yapı, karar alma, esneklik ve sürdürülebilirlik bağlamında işletmeler için arzu edilen bir yapıdır.

Bu çalışmada, doğal taş sektöründe faaliyet gösteren ve sektörel rekabet avantajına sahip olan bir işletmede makine seçimi araştırılmıştır. Problem seçiminin makine seçimi olarak seçilmesinin nedeni, doğru makine ile uzun süreli etkin ve verimli bir şekilde üretim yapabilmektir, bu da kaynakların doğru dağıtılmasında önem arz etmektedir. Doğal taş sektöründe- özelliğine bağlı değişmekle birlikte- makine seçimi büyük bir yatııım anlamına gelmekte, bu da karar vericiler için ekonomik anlamda baskı unsuru olmaktadır.

Belirtilen nedenler doğrultusunda, karar alma işletmeler için çok daha nesnel ve akılcı bir takım nedenlerle işleyen bir mekanizma özelliği taşımalıdır. Bu mekanizma, hem her işletmeye özgü bir takım misyon, vizyon ve stratejik bakış açısını içeren, hem de bağlı bulunan çevresel etkiler bağlamında değerlendirilebildiği takdirde işlevsel olabilecektir. Bu nedenle, en uygun makinenin seçilebilmesi için Entropi ve TOPSIS yöntemleri kullanılarak bir çözüm yapılmışıır. Entropi yöntemi ile karar alıcıların sezgisel yargılarından ve tutumlarından bağımsız bir şekilde, makine seçimi için belirlenen karar kriterlerinin ağırlıkları belirlenmişşir. Ardından TOPSIS yöntemi ile karar kriterlernin ağırlıkları hesaba katılarak, alternatif makineler önem değerlerine göre sıralandırılmıştır. Seçilen analiz yöntemleri aynı zamanda kullanıcı dostu olarak adlandırılabilir. Entropi ve TOPSIS yöntemlerinin bu anlamda öne çıkan avantajı, uygulanması ve yorumlanmasının görece kolay olmasıdır. Her iki yöntem için herhangi bir program veya yazılım kullanımı söz konusu olmayıp, Excel programı ile çözülebilmektedir. Bu ise, sadece doğal taş sektörü için değil, kaynak aktarım problemlerinde söz konusu olan herhangi bir olgu (tedarikçi seçimi, araç seçimi, kullanılacak teknoloji vb.) için herhangi bir sektördeki başka karar vericiler tarafından da uygulanmasını kolaylaştırmaktadır. Bu sayede kaynakların rasyonel kullanıldığı ve alınan kararların sorumluluğunun paylaşıldığı bir yapı ortaya çıkabilecektir.

$\mathrm{Bu}$ çalışma konunun genel çerçevesinin değerlendirildiği giriş bölümü ile birlikte altı bölümden oluşmaktadır. ÇKKV yöntemlerinin ve ilgili makalelerde yer alan problemlerin örneklendirildiği literatür taramas1, Entropi, TOPSIS ve uygulama bölümüne ek, son olarak sonuç bölümü yer almaktadır.

\section{LİTERATÜR TARAMASI}

Gerek bireyler olsun, gerekse de işletmeler olsun hayatlarının her döneminde çok boyutlu problemler için karar almak zorundadırlar. Çoğu zaman, birbirleriyle çatışan birçok kriterin ve amaçların gerçekleşmesiyle karşı karşıya kalmaktadırlar. Çok kriterli karar verme teknikleri, bu durumda "en iyi/uygun" çözüme ulaşmada 
yardımcı olmaktadır. Karar vericiler karar alma noktasında, bu tür problemlerin üstesinden gelmede çok kriterli karar verme tekniklerinden faydalanmakta yarar sağlamaktadır.

İşletmelerin karar vermesi gereken en önemli konularının arasında makine seçim problemleri de yer almaktadır. Literatürde de ÇKKV yöntemleri kullanılarak yapılan makine seçimi problemleri aşağıda Tablo 1'de özetlenmiş̧ir.

Tablo 1. ÇKKV yöntemleri kullanılarak makine seçimine ilişkin çalışmalar

\begin{tabular}{lll}
\hline Konu & Yöntem/Yöntemler & Referanslar \\
\hline Tekstil işletmesinde makine seçimi & EDAS; Bulanık AHS; Entropi-ROV ve CRITIC-ROV; Bulanık VIKOR & {$[1,2,3,4]$} \\
Gemi inşada ana makine seçimi & AHP, TOPSIS ve PROMETHEE; TOPSIS, MOORA, VIKOR; AHP- & {$[5,6,7]$} \\
$\begin{array}{l}\text { Makine seçimini etkileyen kriterlerin } \\
\text { değerlendirilmesi }\end{array}$ & SMART & {$[8]$} \\
Mermer kesim makinesi seçimi & Bulanık DEMATEL & {$[9.10]$} \\
CNC makinesi seçimi & Bulanık DEMATEL-Bulanık VIKOR; KEMIRA-M VE COPRAS & {$[11,12]$} \\
Kablo üretiminde makine seçimi & Bulanık AHS-Bulanık TOPSIS; Bulanık VIKOR & {$[13]$} \\
Taşımacılıkta çekici araç seçimi & Bulanık DEMATEL-Bulanık PROMETHEE & {$[14]$} \\
Tarım makinesi seçimi & AHP, Entropi ve TOPSIS & {$[15]$} \\
Esnek üretim sistemleri seçimi & AHP ile Bütünleşik Gri İlişkisel Analiz & {$[16]$} \\
Yapı makinesi seçimi & AHS-Bulanık PROMETHEE & {$[17]$} \\
Alșşılmamış imalat & VIKOR & {$[18]$} \\
seçimi & Bulanık AHP, Bulanık TOPSIS & {$[19]$} \\
Transpalet seçimi & AHP, EDAS & {$[20]$} \\
Paketleme makinesi seçimi & Sezgisel Bulanık TOPSIS & {$[21]$} \\
Pres makinesi seçimi & Bulanık SMART ve Bulanık Ağırlıklı Aksiyomatik Tasarım & {$[22]$} \\
\hline
\end{tabular}
özetlenmiştir.

Literatürde Entropi-TOPSIS yöntemlerinin birlikte kullanıldı̆̆g çalışmalar ise aşağıda Tablo 2'de

Tablo 2. Entropi-TOPSIS yöntemlerinin birlikte kullanılmasına ilişkin çalışmalar

\begin{tabular}{ll}
\hline Konu & Referanslar \\
\hline BíST’te işlem gören firmaların performansının incelenmesi & {$[23,24,25,26,27]$} \\
Futbol takımlarının finansal ve sportif etkinliklerinin analiz edilmesi & {$[28]$} \\
Enerji sektöründe kurumsal sürdürülebilirlik performansının ölçümü. & {$[29]$} \\
AB ülkelerinin Ar-Ge performanslarının ölçülmesi & {$[30]$} \\
Organize sanayi bölgelerinin yatırım ortamının değerlendirilmesi & {$[31]$} \\
Endüstri İşletmelerinde AR-GE Projelerini Öncelik Siralaması & {$[32]$} \\
Havaalanlarının hizmet kalitesi performansları değerlendirilmesi & {$[33]$} \\
Akademik personelin duygusal performanslarının ölçülmesi & {$[34]$} \\
Yeşil Tedarikçi seçimi & {$[35]$} \\
Yeşil teknoloji yeniliklerinin ekonomik ve ekolojik değerlendirilmesi & {$[36]$} \\
Elektrikli şarj istasyonu seçimi & {$[37]$} \\
Yeraltı suları kalitesi sıralaması & {$[38]$} \\
Demir-Çelik sanayinde simbiotik teknoloji değerlendirmesi & {$[39]$} \\
Turizm destinasyon değerlendirmesi & {$[40]$} \\
\hline
\end{tabular}


Tablo 1.'de görüldüğ̈̈ üzere ÇKKV yöntemleri çeşitli sektörlerde makine seçimleri problemlerinde kullanılmıştır. Tablo 2.'de ise, Entropi ve TOPSIS yöntemlerinin çok çeşitli alanlarda kullanıldığı görülmektedir. $\mathrm{Bu}$ alanlar Avrupa Birliği'nin AR-GE performans ölçümünden, tedarikçi seçimine; kullanılan teknoloji değerlendirmesinden, organizasyonel ve sektörel etkinlik ölçümüne kadar farklılık göstermektedir.

\section{ENTROPI YÖNTEMI}

Literatürde Entropi kavramı ilk kez 1865 yılında Rudolph Clausius tarafından bir sistemde meydana gelen düzensizliğin ve belirsizliğin bir ölçüsü olarak ifade edilmiştir [40]. Günümüzde fizik, matematik ve mühendislik bilimlerinde yaygın olarak karşılaşılan Entropi kavramı Shannon'ın (1948) enformasyon teorisine uyarlanmıştır. Mevcut verinin elde edildiği faydalı bilginin miktarını ölçmede kullanılan Entropi yöntemi objektif kararların alınmasında kullanılmaktadır [12]. Entropi yönteminin aşamaları aşağıdaki gibi açıklanabilir $[41,42]$.

$a_{i}$ : alternatif $i ; i=1,2,3, \ldots, m$

$c_{\mathrm{j}}:$ kriter $\mathrm{j} ; \mathrm{j}=1,2,3, \ldots, \mathrm{n}$

$\mathrm{x}_{\mathrm{ij}}$ : alternatif i'nin $\mathrm{j}$ kriteri açısından performans değeri

D: karar matrisi

Karar matrisi Eşitlik 1'deki gibi oluşturulabilir.

$$
D=\left[\begin{array}{cccc}
x_{11} & x_{12} & \cdots & x_{1 n} \\
x_{21} & x_{22} & \cdots & x_{2 n} \\
\cdots & \cdots & \cdots & \cdots \\
x_{m 1} & x_{m 2} & \cdots & x_{m n}
\end{array}\right]
$$

Karar matrisinde birbirinden farklı indeks boyutlarının eşölçülemezlik üzerindeki etkilerini yok etmek amacıyla indeksler çeşitli yöntemlerle standartlaştırlabilmektedir. Fayda ve maliyet indekslerine göre kriterler Eşitlik (2) ve Eşitlik (3) yardımıyla standartlaştırılır.

$$
\begin{aligned}
& r_{i j}=x_{i j} / \max _{i j}(i=1, \ldots, m ; j=1, \ldots, n) \\
& r_{i j}=\min _{i j} / x_{i j}(i=1, \ldots, m ; j=1, \ldots, n)
\end{aligned}
$$

$p_{\mathrm{ij}}$ : alternatif i'nin $\mathrm{j}$ kriteri açısından normalize edilmiş performans değeri

$$
p_{i j}=\frac{x_{i j}}{\sum_{i=1}^{m} x_{i j}} \quad \forall i, j
$$

ND: Normalize edilmiş karar matrisi

Normalize edilmiş performans değerleri Eşitlik 5'deki gibi hesaplanabilir. 


$$
N D=\left[\begin{array}{cccc}
p_{11} & p_{12} & \cdots & p_{1 n} \\
p_{21} & p_{22} & \cdots & p_{2 n} \\
\cdots & \cdots & \cdots & \cdots \\
p_{m 1} & p_{m 2} & \cdots & p_{m n}
\end{array}\right]
$$

$E_{j}=$ kriter $j$ için entropi değeri; $j=1,2,3, \ldots, n$

k:sabit

Entropi değerleri Eşitlik 6'daki gibi hesaplanabilir.

$$
E_{j}=-k \sum_{i=1}^{m}\left[\left(p_{i j}\right)\left(\ln \left(p_{i j}\right)\right)\right] \quad \forall j
$$

Yöntemdeki sabit değer Eşitlik 7'deki gibi hesaplanabilir.

$$
k=\frac{1}{\ln (m)}
$$

$d_{j}$ : kriter i için belirsizlik derecesi; $j=1,2,3, \ldots, n$

Belirsizlik derecesi Eşitlik 8'deki gibi hesaplanabilir.

$$
d_{j}=1-E_{j}
$$

$\mathrm{W}_{\mathrm{j}}$ : kriter $\mathrm{j}$ için ağırlık değeri; $\mathrm{j}=1,2,3, \ldots, \mathrm{n}$

Ağırlık değerleri Eşitlik 9'daki gibi hesaplanabilir.

$$
w_{j}=\frac{d_{j}}{\sum_{j=1}^{n} d_{j}}
$$

\section{TOPSIS YÖNTEMI}

Çok Kriterli Karar Verme (ÇKKV) problemlerinde, alternatifler, belirli kriterler altında analiz edilerek, performans sıralaması yapılmaktadır. Literatürde kullanılan ÇKKV metotlarından birisi olan, TOPSIS (Technique for Order Preference by Similarity to İdeal Solution) yöntemi 1981 yılinda Hwang ve Yoon tarafından ortaya konulmuştur [43]. Bu yöntem, pozitif-ideal çözüme en yakın ve negatif-ideal çözüme en uzak alternatiflerin performans sıralamasını yapmaktadır. TOPSIS işleminde $\mathrm{m}$ alternatifleri, $\mathrm{n}$ kriterleri değerlendiren aşamaları aşağıda yer almaktadır:

Karar Matrisi (A) Eşitlik 10'daki gibi oluşturulur.

$$
A=\left[\begin{array}{cccc}
a_{11} & a_{12} & \cdots & a_{1 n} \\
a_{21} & a_{22} & \cdots & a_{2 n} \\
\vdots & \vdots & \cdots & \vdots \\
a_{m 1} & a_{m 2} & \cdots & a_{m n}
\end{array}\right]
$$


Normalleştirilmiş Karar Matrisinin (R) Eşitlik 11 kullanılarak elde edilir. Bu adımda, verileri ölçekten normalleştirmek için tüm sütun değerleri kareli toplamlarına bölünür.

$$
r_{i j}=\frac{a_{i j}}{\sqrt{\sum_{i=1}^{m} a_{i j}^{2}}}(i=1,2, \ldots, \text { m ve } j=1,2, \ldots, n)
$$

Normalleştirilmiş karar matrisi R Eşitlik 12'deki gibi elde edilir

$$
R=\left[\begin{array}{cccc}
r_{11} & r_{12} & \cdots & r_{1 n} \\
r_{21} & r_{22} & \cdots & r_{2 n} \\
\vdots & \vdots & \cdots & \vdots \\
r_{m 1} & r_{m 2} & \cdots & r_{m n}
\end{array}\right]
$$

Normalize Matrisin Ağırlıklandırılması için R matrisinin her sütunundaki elemanları ilgili wj değeri ile çarpılarak ağırlıklandırılmış normalize matris ( V matrisi) Eşitlik 13 gibi elde edilir.

$$
V=\left[\begin{array}{cccc}
w_{1} r_{11} & w_{2} r_{12} & \cdots & w_{n} r_{1 n} \\
w_{1} r_{21} & w_{2} r_{22} & \cdots & w_{n} r_{2 n} \\
\vdots & \vdots & \cdots & \vdots \\
w_{1} r_{m 1} & w_{2} r_{m 2} & \cdots & w_{n} r_{m n}
\end{array}\right]
$$

İdeal ve ideal olmayan çözümleri aşağıdaki Eşitlik (14) ve Eşitlik (15) yoluyla elde edilmektedir:

$$
\begin{aligned}
& A^{*}=\left\{\left(\max _{j} v_{i j} \mid j \in J\right),\left(\min _{j} v_{i j} \mid j \in J\right\}\right. \\
& A^{-}=\left\{\left(\min _{j} v_{i j} \mid j \in J\right),\left(\max _{j} v_{i j} \mid j \in J\right\}\right.
\end{aligned}
$$

İdeal ve İdeal Olmayan Çözümlere Uzaklıkların Hesaplanmasında Öklid metriği kullanılmaktadır. Alternatiflerin ideal çözümden ve negatif ideal çözümden uzaklaşma değerleri sırasıyla; ideal uzaklık $\left(S i^{*}\right)$ ve ideal olmayan uzaklık $\left(\mathrm{Si}^{-}\right)$olarak Eşitlik 16 ve Eşitlik 17'deki gibi verilmektedir.

İdeal uzaklık:

$$
S_{i}^{*}=\sqrt{\sum_{j=1}^{n}\left(v_{i j}-v_{j}^{*}\right)^{2}} \quad i=1,2, \ldots, m
$$

İdeal olmayan uzaklık:

$$
S_{i}^{-}=\sqrt{\sum_{j=1}^{n}\left(v_{i j}-v_{j}^{-}\right)^{2}} \quad i=1,2, \ldots, m
$$

İdeal Çözüme Göreceli Yakınlık, ideal ve ideal olmayan çözümlere olan uzaklıklardan Eşitlik 18'de belirtildiği gibi hesaplanmaktadır. 


$$
C_{i}^{*}=\frac{S_{i}^{-}}{S_{i}^{-}+S_{i}^{*}}
$$

$C i^{*}$ değeri $0 \leq C i^{*} \leq 1$ değer almaktadır. $C i^{*}=1$ ilgili alternatifin ideal alternatife eşit, $C i^{*}=0$ ise ideal olmayan çözüme eşit olduğunu göstermektedir.

\section{UYGULAMA}

Çalışma kapsamında mermer üretimi yapan bir imalat işletmesi için mermer işleme makinesi seçimi yapılacaktır. Çalışma sonucuna göre işletmeye alınması düşünülen mermer işleme makinesi, mermerlerin kesimi, konturlanması, profillendirilmesi ve şekillendirilmesi gibi işlemler için kullanılmaktır.

Çalışma kapsamında öncelikle işletme için en uygun mermer işleme makinesinin seçilebilmesi amacıyla satın alma kararı üzerinde etkili olduğu düşünülen kriterler işletme sahibi görüşleri doğrultusunda belirlenmiştir. $\mathrm{Bu}$ kriterler motor gücü, devir hızı, Z ekseni, maksimum testere çapı ve fiyattır. Bu kriterler açısından işletme için uygun olabileceği düşünülen farklı marka ve/veya modelde alternatif on dört adet mermer işleme makinesinin değerlendirilmesine karar verilmiştir. Alternatif makinelerin belirlenen kriterler açısından özellikleri ve karar kriterlerinin amaçları Tablo 3 'te yer almaktadır.

Tablo 3. Alternatifleri ve Kriterleri içeren karar matrisi

\begin{tabular}{|c|c|c|c|c|c|}
\hline Alternatifler & $\begin{array}{c}\text { Motor Gücü } \\
(\mathbf{k W})\end{array}$ & Devir hızı (dev/dk) & $\begin{array}{c}\text { Z Ekseni } \\
(\mathrm{mm})\end{array}$ & $\begin{array}{c}\text { Maksimum testere çapı } \\
(\mathbf{m m})\end{array}$ & Fiyat $(€)$ \\
\hline $\mathrm{A} 1$ & 13 & 5000 & 320 & 600 & 106.400 \\
\hline $\mathrm{A} 2$ & 26,5 & 6000 & 700 & 800 & 161.030 \\
\hline A3 & 13,5 & 15000 & 420 & 250 & 130.500 \\
\hline A4 & 13,5 & 15000 & 420 & 250 & 140.000 \\
\hline A5 & 13,5 & 15000 & 600 & 250 & 152.000 \\
\hline A6 & 13,5 & 15000 & 900 & 250 & 157.000 \\
\hline A7 & 13,5 & 9000 & 580 & 625 & 158.000 \\
\hline A8 & 31 & 7500 & 1000 & 900 & 176.000 \\
\hline A9 & 13 & 4500 & 400 & 625 & 114.285 \\
\hline A10 & 23,5 & 8000 & 700 & 825 & 205.135 \\
\hline A11 & 32 & 8000 & 1000 & 1000 & 214.398 \\
\hline A12 & 20 & 12000 & 850 & 625 & 204.000 \\
\hline A13 & 20 & 8000 & 700 & 700 & 172.000 \\
\hline A14 & 20 & 8000 & 900 & 900 & 175.000 \\
\hline Amaç & Fayda & Fayda & Fayda & Fayda & Maliyet \\
\hline
\end{tabular}

İlk olarak karar matrisinin fayda ve maliyet kriterine göre normalizasyon işlemi Eşitlik (2) ve Eşitlik (3) yardımıyla yapılmıştır (Tablo 4). Daha sonra Eşitlik (4)'te verildiği gibi her bir ilgili kriter değerinin toplamı, ilgili alternatifin kriter değerine bölünerek karar matrisi normalize edilmiştir (Tablo 5). 


\begin{tabular}{|c|c|c|}
\hline & $\begin{array}{l}\text { BŞEÜ Fen Bilimleri Dergisi } \\
7(2), 714-729,2020\end{array}$ & $\begin{array}{r}\text { BSEU Journal of Science } \\
\text { DOI: } 10.35193 / \text { bseufbd.726608 }\end{array}$ \\
\hline VERSI & & 58-7575 (http://dergipark.gov.tr/bseufbd) \\
\hline
\end{tabular}

Tablo 4. Fayda ve Maliyet Kriterlerinin Hesaplanması

\begin{tabular}{cccccc}
\hline Alternatifler & Motor Gücü $(\mathbf{k W})$ & $\begin{array}{c}\text { Devir hızı } \\
(\mathbf{d e v} / \mathbf{d k})\end{array}$ & $\begin{array}{c}\text { Z Ekseni } \\
(\mathbf{m m})\end{array}$ & $\begin{array}{c}\text { Maksimum testere } \\
\text { capı (mm) }\end{array}$ & Fiyat (€) \\
\hline A1 & 0,4063 & 0,3333 & 0,3200 & 0,6000 & 1,0000 \\
A2 & 0,8281 & 0,4000 & 0,7000 & 0,8000 & 0,6607 \\
A3 & 0,4219 & 1,0000 & 0,4200 & 0,2500 & 0,8153 \\
A4 & 0,4219 & 1,0000 & 0,4200 & 0,2500 & 0,7600 \\
A5 & 0,4219 & 1,0000 & 0,6000 & 0,2500 & 0,7000 \\
A6 & 0,4219 & 1,0000 & 0,9000 & 0,2500 & 0,6777 \\
A7 & 0,4219 & 0,6000 & 0,5800 & 0,6250 & 0,6734 \\
A8 & 0,9688 & 0,5000 & 1,0000 & 0,9000 & 0,6045 \\
A9 & 0,4063 & 0,3000 & 0,4000 & 0,6250 & 0,9310 \\
A10 & 0,7344 & 0,5333 & 0,7000 & 0,8250 & 0,5187 \\
A11 & 1,0000 & 0,5333 & 1,0000 & 1,0000 & 0,4963 \\
A12 & 0,6250 & 0,8000 & 0,8500 & 0,6250 & 0,5216 \\
A13 & 0,6250 & 0,5333 & 0,7000 & 0,7000 & 0,6186 \\
A14 & 0,6250 & 0,5333 & 0,9000 & 0,9000 & 0,6080 \\
\hline Amaç & Fayda & Fayda & Fayda & Fayda & Maliyet \\
\hline
\end{tabular}

Tablo 5. Normalize Edilmiş Karar Matrisi $\left(\boldsymbol{P}_{i j}\right.$ Matrisi)

\begin{tabular}{cccccc}
\hline Alternatifler & Motor Gücü $(\mathbf{k W})$ & Devir hızı (dev/dk) & $\begin{array}{c}\text { Z Ekseni } \\
(\mathbf{m m})\end{array}$ & $\begin{array}{c}\text { Maksimum testere çapı } \\
(\mathbf{m m})\end{array}$ & Fiyat (€) \\
\hline A1 & 0,0488 & 0,0368 & 0,0337 & 0,0698 & 0,1043 \\
A2 & 0,0994 & 0,0441 & 0,0738 & 0,0930 & 0,0689 \\
A3 & 0,0507 & 0,1103 & 0,0443 & 0,0291 & 0,0851 \\
A4 & 0,0507 & 0,1103 & 0,0443 & 0,0291 & 0,0793 \\
A5 & 0,0507 & 0,1103 & 0,0632 & 0,0291 & 0,0730 \\
A6 & 0,0507 & 0,1103 & 0,0948 & 0,0291 & 0,0707 \\
A7 & 0,0507 & 0,0662 & 0,0611 & 0,0727 & 0,0703 \\
A8 & 0,1163 & 0,0551 & 0,1054 & 0,1047 & 0,0631 \\
A9 & 0,0488 & 0,0331 & 0,0421 & 0,0727 & 0,0971 \\
A10 & 0,0882 & 0,0588 & 0,0738 & 0,0959 & 0,0541 \\
A11 & 0,1201 & 0,0588 & 0,1054 & 0,1163 & 0,0518 \\
A12 & 0,0750 & 0,0882 & 0,0896 & 0,0727 & 0,0544 \\
A13 & 0,0750 & 0,0588 & 0,0738 & 0,0814 & 0,0645 \\
A14 & 0,0750 & 0,0588 & 0,0948 & 0,1047 & 0,0634 \\
\hline Amaç & Fayda & Fayda & Fayda & Fayda & Maliyet \\
\hline
\end{tabular}

Entropi ( $\boldsymbol{E j}$ ) Değerinin ve K Değerinin Hesaplanmasında Tablo 6'daki her bir kriter değerinin (Pij), logaritma değeri alınmış (lnij), alınan bu logaritma değerleriyle kriter değerleri çarpılmaktadır. 
Tablo 6. $\boldsymbol{P}_{\boldsymbol{i j} \mathrm{x}} \boldsymbol{l n}_{\boldsymbol{i} j}$ Değerinin Hesaplanması

\begin{tabular}{|c|c|c|c|c|c|}
\hline Alternatifler & Motor Gücü (kW) & $\begin{array}{c}\text { Devir hızı } \\
\text { (dev/dk) }\end{array}$ & $\begin{array}{c}\text { Z Ekseni } \\
(\mathrm{mm})\end{array}$ & $\begin{array}{c}\text { Maksimum testere çapı } \\
(\mathbf{m m})\end{array}$ & Fiyat (€) \\
\hline A1 & $-0,1473$ & $-0,1214$ & $-0,1143$ & $-0,1858$ & $-0,2358$ \\
\hline A2 & $-0,2295$ & $-0,1377$ & $-0,1923$ & $-0,2209$ & $-0,1844$ \\
\hline A3 & $-0,1511$ & $-0,2432$ & $-0,1380$ & $-0,1029$ & $-0,2096$ \\
\hline A4 & $-0,1511$ & $-0,2432$ & $-0,1380$ & $-0,1029$ & $-0,2010$ \\
\hline A5 & $-0,1511$ & $-0,2432$ & $-0,1746$ & $-0,1029$ & $-0,1911$ \\
\hline A6 & $-0,1511$ & $-0,2432$ & $-0,2234$ & $-0,1029$ & $-0,1873$ \\
\hline A7 & $-0,1511$ & $-0,1797$ & $-0,1708$ & $-0,1905$ & $-0,1866$ \\
\hline A8 & $-0,2503$ & $-0,1598$ & $-0,2371$ & $-0,2362$ & $-0,1743$ \\
\hline A9 & $-0,1473$ & $-0,1128$ & $-0,1335$ & $-0,1905$ & $-0,2265$ \\
\hline A10 & $-0,2141$ & $-0,1667$ & $-0,1923$ & $-0,2249$ & $-0,1578$ \\
\hline A11 & $-0,2545$ & $-0,1667$ & $-0,2371$ & $-0,2502$ & $-0,1533$ \\
\hline A12 & $-0,1943$ & $-0,2142$ & $-0,2161$ & $-0,1905$ & $-0,1584$ \\
\hline A13 & $-0,1943$ & $-0,1667$ & $-0,1923$ & $-0,2042$ & $-0,1769$ \\
\hline A14 & $-0,1943$ & $-0,1667$ & $-0,2234$ & $-0,2362$ & $-0,1749$ \\
\hline Toplam & $-2,5816$ & $-2,5649$ & $-2,5831$ & $-2,5414$ & $-2,6178$ \\
\hline
\end{tabular}

Bir sonraki aşamada Tablo 7'te bulunan $E j$ değeri Eşitlik (6), dj değeri Eşitlik (8) ve wj değeri Eşitlik (9) yardımıyla hesaplanmıştır. $\mathrm{K}=1 / \mathrm{ln} . \mathrm{n}$, sabit bir sayı olmak üzere $0 \leq e j \leq 1$ olmasını sağlar. Bu çalışmada, $\mathrm{n}=$ 14 olduğundan $\mathrm{K}=1 / \ln 14=0,3789$ olarak hesaplanmıştır.

Tablo 7. Entropi Değerinin Hesaplanması

\begin{tabular}{ccccc}
\hline Alternatifler & Motor Gücü (kW) & $\begin{array}{c}\text { Devir hız } \\
(\mathbf{d e v} / \mathbf{d k})\end{array}$ & $\begin{array}{c}\text { Z Ekseni } \\
(\mathbf{m m})\end{array}$ & $\begin{array}{c}\text { Maksimum testere çapı } \\
(\mathbf{m m})\end{array}$ \\
\hline $\mathbf{E j}$ & 0,978229031 & 0,97189381 & 0,9788055 & 0,962982355 \\
$\mathbf{d j}$ & 0,021770969 & 0,02810619 & 0,0211945 & 0,037017645 \\
$\mathbf{w j}$ & 0,187418129 & 0,24195565 & 0,1824557 & 0,318671062 \\
\hline
\end{tabular}

Entropi yöntemi sonucunda elde edilmiş kriter ağırlıklarına bakıldığında, en önemli kriterin maksimum testere çapı olduğu belirlenmiştir. Sonrasında kriter ağırlıkları sırasıyla devir hızı, motor gücü, z ekseni ve fiyat olarak sıralanmıştır.

$\mathrm{Bu}$ aşamadan sonra alternatifleri değerlendirmek için TOPSíS yöntemi uygulanmıştır. Tablo 8'de Eşitlik (11) yardımıyla elde edilen normalize karar matrisi verilmiştir. 
Tablo 8. Normalize edilmiş karar matrisi

\begin{tabular}{|c|c|c|c|c|c|}
\hline Alternatifler & Motor Gücü (kW) & Devir hızı (dev/dk) & Z Ekseni (mm) & $\begin{array}{c}\text { Maksimum testere çapı } \\
(\mathbf{m m})\end{array}$ & Fiyat (€) \\
\hline A1 & 0,1724 & 0,1283 & 0,1199 & 0,2407 & 0,1725 \\
\hline $\mathrm{A} 2$ & 0,3513 & 0,1540 & 0,2623 & 0,3210 & 0,2611 \\
\hline A3 & 0,1790 & 0,3849 & 0,1574 & 0,1003 & 0,2116 \\
\hline A4 & 0,1790 & 0,3849 & 0,1574 & 0,1003 & 0,2270 \\
\hline A5 & 0,1790 & 0,3849 & 0,2248 & 0,1003 & 0,2464 \\
\hline A6 & 0,1790 & 0,3849 & 0,3372 & 0,1003 & 0,2545 \\
\hline A7 & 0,1790 & 0,2310 & 0,2173 & 0,2508 & 0,2561 \\
\hline A8 & 0,4110 & 0,1925 & 0,3747 & 0,3611 & 0,2853 \\
\hline A9 & 0,1724 & 0,1155 & 0,1499 & 0,2508 & 0,1853 \\
\hline A10 & 0,3116 & 0,2053 & 0,2623 & 0,3310 & 0,3326 \\
\hline A11 & 0,4243 & 0,2053 & 0,3747 & 0,4012 & 0,3476 \\
\hline A12 & 0,2652 & 0,3079 & 0,3185 & 0,2508 & 0,3307 \\
\hline A13 & 0,2652 & 0,2053 & 0,2623 & 0,2808 & 0,2788 \\
\hline A14 & 0,2652 & 0,2053 & 0,3372 & 0,3611 & 0,2837 \\
\hline
\end{tabular}

R matrisinin her sütunundaki elemanları ilgili wj değeri ile çarpılarak elde edilen ağırlıklandırılmış normalize matris Tablo 9' da verilmiştir.

Tablo 9. Ağırlıklandırılmış karar matrisi

\begin{tabular}{|c|c|c|c|c|c|}
\hline wj & 0,1874 & 0,2420 & 0,1825 & 0,3187 & 0,0695 \\
\hline Alternatifler & Motor Gücü (kW) & Devir hızı (dev/dk) & Z Ekseni (mm) & $\begin{array}{l}\text { Maksimum testere çap1 } \\
(\mathrm{mm})\end{array}$ & Fiyat $(€)$ \\
\hline A1 & 0,0323 & 0,0310 & 0,0219 & 0,0767 & 0,0120 \\
\hline $\mathrm{A} 2$ & 0,0658 & 0,0373 & 0,0479 & 0,1023 & 0,0181 \\
\hline A3 & 0,0335 & 0,0931 & 0,0287 & 0,0320 & 0,0147 \\
\hline A4 & 0,0335 & 0,0931 & 0,0287 & 0,0320 & 0,0158 \\
\hline A5 & 0,0335 & 0,0931 & 0,0410 & 0,0320 & 0,0171 \\
\hline A6 & 0,0335 & 0,0931 & 0,0615 & 0,0320 & 0,0177 \\
\hline A7 & 0,0335 & 0,0559 & 0,0396 & 0,0799 & 0,0178 \\
\hline A8 & 0,0770 & 0,0466 & 0,0684 & 0,1151 & 0,0198 \\
\hline A9 & 0,0323 & 0,0279 & 0,0273 & 0,0799 & 0,0129 \\
\hline A10 & 0,0584 & 0,0497 & 0,0479 & 0,1055 & 0,0231 \\
\hline A11 & 0,0795 & 0,0497 & 0,0684 & 0,1279 & 0,0242 \\
\hline A12 & 0,0497 & 0,0745 & 0,0581 & 0,0799 & 0,0230 \\
\hline A13 & 0,0497 & 0,0497 & 0,0479 & 0,0895 & 0,0194 \\
\hline A14 & 0,0497 & 0,0497 & 0,0615 & 0,1151 & 0,0197 \\
\hline
\end{tabular}

Ele alınan problem için Eşitlik (14) ve Eşitlik (15) kullanılarak belirlenen İdeal ve İdeal Olmayan Çözüm Değerleri aşağıda Tablo 10'da verilmiştir. Kriterlerin fayda ya da maliyet kriteri olma durumu tespit edilmiştir. 
Tablo 10. İdeal ve ideal olmayan çözüm değerleri

\begin{tabular}{ccccccc}
\hline & $\mathrm{W}+$ & $\mathrm{W}+$ & $\mathrm{W}+$ & $\mathrm{W}+$ & $\mathrm{W}-$ & $\mathrm{K} 5$ \\
\hline $\mathrm{K} 1$ & $\mathrm{~K} 2$ & $\mathrm{~K} 3$ & $\mathrm{~K} 4$ & 0,0120 \\
$\mathrm{Aj}+$ & 0,0795 & 0,0931 & 0,0683 & 0,1278 & 0,0319 & 0,0242 \\
\hline
\end{tabular}

Eşitlik (16) ve Eşitlik (17) kullanılarak elde edilen uzaklık değerleri ile Eşitlik (18) kullanılarak elde edilen göreli yakınlık sonuçları Tablo 11'de verilmiştir.

Tablo 11. Uzaklık Değerleri ve Göreli Yakınlık Sonuçları

\begin{tabular}{ccccc}
\hline Alternatifler & si+ & si- & Ci+ & Siralama \\
\hline A1 & 0,1042 & 0,0635 & 0,6725 & 12 \\
A2 & 0,0665 & 0,0875 & 1,4038 & 6 \\
A3 & 0,1135 & 0,0684 & 0,6713 & 13 \\
A4 & 0,1136 & 0,0682 & 0,6686 & 14 \\
A5 & 0,1099 & 0,0691 & 0,6979 & 9 \\
A6 & 0,1067 & 0,0756 & 0,7842 & 8 \\
A7 & 0,0816 & 0,0696 & 0,9227 & 2 \\
A8 & 0,0490 & 0,1061 & 2,2715 & 11 \\
A9 & 0,1023 & 0,0658 & 0,7096 & 4 \\
A10 & 0,0581 & 0,0914 & 1,6631 & 1 \\
A11 & 0,0451 & 0,1175 & 2,7213 & 5 \\
A12 & 0,0613 & 0,0820 & 1,4190 & 5 \\
A13 & 0,0687 & 0,0775 & 1,2057 & 7 \\
A14 & 0,0552 & 0,1042 & 1,9906 & 3
\end{tabular}

Tablo 11 incelendiğinde, 2.7213 değeri en büyük göreli yakınlık değerine sahip olmasından dolayı en ideal makinenin Alternatif 11 olduğu ve en son tercih edilecek makinenin de 0,6686 göreli değeri ile Alternatif 4 olduğu tespit edilmiştir. Bu sonuçlara göre; ideal olmayan çözüme en uzak olan alternatifin, Alternatif 11 olduğu ve ideal olmayan çözüme en yakın alternatifin ise Alternatif 4 olduğu söylenebilmektedir.

\section{SONUÇ VE ÖNERILIER}

Makine seçimi problemi sadece doğal taş (mermer ve granit vb.) sektöründe faaliyet gösteren değil, diğer tüm sektörlerde öne çıkan bir maliyet unsuru olarak yer almaktadır. Makine problemleri uzun vadeli amorti sürelerine sahip olma özellikleri ile diğer kriterler bağlamında değerlendirilmesi gereken bir karar problemidir. Makine seçimi karar problemi doğrultusunda Entropi ve TOPSIS yöntemleri ile analizler yapılmış olup, ilgili yöntemlerin bu tür bir problemde kullanışlı olma durumu, literatürden örneklendirmeler ile tartışılmıştır.

Analiz sonuçları en önemli kriterlerin başta maksimum testere çapı olmak üzere, sonrasında kriter ağırlıkları sırasıyla devir hızı, motor gücü, z ekseni ve fiyat olarak sıralanmıştır. Bu sonuç, satın alımlarda fiyat unsurunun minimize edilmesi gerekliliğinin aksine bir durum olarak ortaya çıkmıştır. Seçilen A11 alternatifi ile en düşük fiyatlı makine alternatifi olan A1 arasında \%49, 62 oranında bir fark vardır- en uygun fiyatlı modelin yaklaşık iki katı daha fazla fiyatlıdır. 
İlk akla gelen fiyat kriterinin aksine, makine testere çapı ön plana çıkmıştır. Burada önem arz eden durum, testere çapının, mermer blokların kesiminden oluşan kaybı minimuma indirmesidir. Teknolojik gelişimlerin firmalara ve sektörlere etkisinin de vurgulandığı bu bulgu ile karar almanın sadece firma sahipleri tarafından değil, konunun uzmanlarınca beraber değerlendirilmesi gereklidir. Alınacak her kararın alternatif maliyeti, rekabet avantajını etkileyecektir. Dolayısı ile pay sahibi yaklaşımı her zaman doğru kararı ifade etmemektedir.

Sonuç olarak, makine üreticileri için ürün fiyatının önem derecesinden ziyade teknolojik özellikleri ile piyasada faaliyet göstermesi gerekliliği olduğu vurgulanabilir. En iyi alternatif olarak seçilen A11'in fiyatı diğer 14 makine arasında en yüksek fiyatlı olmasına rağmen, diğer teknolojik özellikleri de içerisinde barındırması ile ilk sırayı almıştır. Bu durumda, sektör uygulayıcıları, rekabet avantajının anlamının derinlemesine inceleyerek, karar verme durumunda çeşitli ÇKKV yöntemlerinden faydalanmaları önerilmektedir. Bütünleşik yöntem yerine tek yöntem tercih edilebilir.

\section{KAYNAKLAR}

[1] Ulutaş, A. (2017). EDAS yöntemi kullanılarak bir tekstil atölyesi için dikiş makinesi seçimi. İşletme Araştırmaları Dergisi, 9(2), 169-183.

[2] Ertuğrul, İ. (2007). Bulanık Analitik Hiyerarşi Süreci ve Bir Tekstil İşletmesinde Makine Seçim Problemine Uygulanması. Hacettepe Üniversitesi İktisadi ve İdari Bilimler Fakültesi Dergisi,25(1), 171192.

[3] Akın, N. G. (2019). Makine Seçimi Probleminde Entropi-ROV ve CRITIC-ROV Yöntemlerinin Karşılaştırılması. Dumlupınar Üniversitesi Sosyal Bilimler Dergisi, (62), 20-39.

[4] Faydalı, R., \& Erkan, E. F. (2020). Makine Seçim Probleminin Bulanık VIKOR Yöntemiyle İncelenmesi. Zeki Sistemler Teori ve Uygulamalart Dergisi,3(1), 7-12.

[5] Uzun, S., \& Kazan, H. (2016). Çok Kriterli Karar Verme Yöntemlerinden AHP TOPSIS ve PROMETHEE Karşılaştırılması: Gemi İnşada Ana Makine Seçimi Uygulaması. Journal of Transportation and Logistics, l(1), 99-113.

[6] Uzun, S., \& Yıldırım, B. F. (2016). Equipment Selection in Ship Building Process: TOPSIS, MOORA, VIKOR Application. Eurasian Academy of Sciences Eurasian Business \& Economics Journal, 2, 113-124.

[7] Herişçakar, E. (1999). Gemi Ana Makine Seçiminde Çok Kriterli Karar Verme Yöntemleri AHP ve SMART Uygulaması. Gemi İnşaatı ve Deniz Teknolojisi Teknik Kongresi,99, 240-256.

[8] Organ, A. (2013). Bulanık DEMATEL yöntemiyle makine seçimini etkileyen kriterlerin değerlendirilmesi. Çukurova Üniversitesi Sosyal Bilimler Enstitüsü Dergisi,22(1), 157-172.

[9] Gök Kısa,C.\& Perçin, S. (2017). Bütünleşik Bulanık DEMATEL-Bulanık VIKOR Yaklaşımının Makine Seçimi Problemine Uygulanması. Journal of Yaşar University, 12(48), 249-256.

[10] Kundakcı, N., \& Sarıçalı, G. (2019). Bütünleşik KEMIRA-M ve COPRAS Yöntemi ile Mermer İşletmesi İçin Katrak Makinesi Seçimi. Kafkas Üniversitesi İktisadi ve İdari Bilimler Fakültesi Dergisi,10(20), 10281061.

[11] Perçin, S., \& Ayan, T. Y. (2015). AHS ve Bulanık PROMETHEE Yaklaşımlarıyla Esnek Üretim Sistemleri Seçimi. Marmara Üniversitesi İktisadi ve İdari Bilimler Dergisi, 29(2), 555-575.

[12] Wu, J., Sun, J., Liang, L. And Zha Y. (2011). "Determination of Weights for Ultimate Cross Efficiency Using Shannonentropy", Expert Systems with Applications, 38 (5): 5162-5165. 
[13] Kabadayı, N., \& Dağ, S. (2017). Bulanık DEMATEL Ve Bulanık PROMETHEE Yöntemleri ile Kablo Üretiminde Makine Seçimi. Karadeniz Teknik Üniversitesi Sosyal Bilimler Enstitüsü Sosyal Bilimler Dergisi, 7(14), 239-260.

[14] Görçün, Ö. F. (2019). Uluslararası Taşımacılık İşletmelerinin Çekici Araç Seçimlerinin Entegre AHP, Entropi ve TOPSIS Yöntemleri Kullanılarak Analizi. Afyon Kocatepe Üniversitesi Sosyal Bilimler Dergisi,21(3), 899-922.

[15] Tolun, B. G., \& Tümtürk, A. (2020). AHP ile Bütünleşik Gri İlişkisel Analiz Yöntemi ile Makine Seçimi: Tarım Makinaları Üretim İşletmesinde Bir Uygulama. Yönetim ve Ekonomi: Celal Bayar Üniversitesi İktisadi ve İdari Bilimler Fakültesi Dergisi,27(1), 21-34.

[16] Perçin, S., \& Ayan, T. Y. (2015). AHS ve Bulanık PROMETHEE Yaklaşımlarıyla Esnek Üretim Sistemleri Seçimi. Marmara Üniversitesi İktisadi ve İdari Bilimler Dergisi, 29 (2), 555-575.

[17] Uğur, L. O. . (2015). Yapı Makinesi Satın Alımında VIKOR Çok Kriterli Karar Verme Yönteminin Uygulanmas1. Politeknik Dergisi, 20 (4), 879-885.

[18] Kul, Y., Şeker, A., \& Yurdakul, M. (2014). Bulanık Çok Kriterli Karar Verme Yöntemlerinin Alışılmamış İmalat Yöntemlerinin Seçiminde Kullanılması. Journal of TheFaculty of Engineering and Architecture of Gazi University,29(3), 589-603.

[19] Ulutaş, A., \& Çelik, D. (2019). Transpalet Seçimi Probleminin AHP ve EDAS Yöntemleri İle Değerlendirilmesi. Business \& Management Studies: An International Journal,7(2), 668-686.

[20] Aloini, D., Dulmin, R., \& Mininno, V. (2014). A Peer IF-TOPSIS Based Decision Support System For Packaging Machine Selection. Expert Systems with Applications,41(5), 2157-2165.

[21] Çakır, S., \& Perçin, S. (2013). AB Ülkeleri’nde Bütünleşik Entropi Ağırlık-TOPSIS Yöntemiyle Ar-Ge Performansının Ölçülmesi. Uludağ Üniversitesi İktisadi ve İdari Bilimler Fakültesi Dergisi,32(1), 77-95.

[22] Özgen, A., Tuzkaya, G., Tuzkaya, U. R., \& Özgen, D. (2011). A Multi-Criteria Decision Making Approach for Machine Tool Selection Problem in A Fuzzy Environment. International Journal Of Computational Intelligence Systems, 4(4), 431-445.

[23] Yıldırım, M., Altan, İ. M., \& Gemici, R. (2018). Kurumsal Yönetim İle Finansal Performans Arasındaki İlişkinin Entropi Ağırlıklandırmalı TOPSIS Yöntemi İle Değerlendirilmesi: Bist’te İşlem Gören Gıda Ve İçecek Şirketlerinde Bir Araştırma. Muhasebe ve Vergi Uygulamaları Dergisi,11(2), 130-152.

[24] Aytekin, A., \& Karamaşa, Ç. (2016). BİST'te Faaliyet Gösteren Sigorta Şirketlerinin Finansal Performanslarının Bulanık Shannon Entropi Tabanlı Bulanık TOPSIS Yöntemiyle İncelenmesi. The Journal of Operations Research, Statistics, Econometrics and Management Information Systems ,5(1), 2017

[25] Şahin, A., \& Sarı, E. B. (2019). Entropi Tabanlı TOPSİS ve VIKKOR Yöntemleriyle Bıst-İmalat İşletmelerinin Finansal Ve Borsa Performanslarının Karşılaştırılması. Muhasebe ve Vergi Uygulamaları Dergisi, 12(2), 255-270.

[26] Ece, N. (2019). Holding Şirketlerinin Finansal Performans Siralamasının Entropi Tabanlı TOPSIS Yöntemleri İle İncelenmesi. Finans Ekonomi ve Sosyal Araştırmalar Dergisi (FESA),4(1), 63-73.

[27] Altan, İ. M., \& Yıldırım, M. (2019). Sigorta Sektörünün Finansal Performansının Entropi Ağırlıklandırmalı TOPSIS Yöntemiyle Analizi ve Değerlendirilmesi. Insan ve Toplum Bilimleri Araştırmaları Dergisi,8(1), 345-358. 
[28] Çatı, K., Eş, A., \& Özevin, O. (2017). Futbol takımlarının finansal ve sportif etkinliklerinin Entropi ve TOPSIS yöntemiyle analiz edilmesi: Avrupa'nın 5 büyük ligi ve süper lig üzerine bir uygulama. Uluslararası Yönetim İktisat ve Işletme Dergisi,13(1), 199-222.

[29] Öztel, A., Aydın, B., \& Köse, M. S. (2018). Entropi Tabanlı TOPSIS Yöntemi İle Enerji Sektöründe Kurumsal Sürdürülebilirlik Performansının Ölçümü: Akenerji Örneği. Gümüşhane Üniversitesi Sosyal Bilimler Enstitüsü Elektronik Dergisi,9(24), 1-24.

[30] Çakır, S., \& Perçin, S. (2013). AB Ülkeleri’nde Bütünleşik Entropi Ağırlık-TOPSIS Yöntemiyle Ar-Ge Performansının Ölçülmesi. Uludağ Üniversitesi İktisadi ve İdari Bilimler Fakültesi Dergisi,32(1), 77-95.

[31] Yalçınkaya, Y., Dulupçu, M. A., \& Baykul, A. (2018). TOPSIS Yöntemi ile Organize Sanayi Bölgelerinin Yatırım Ortamının Değerlendirilmesi: İBBS Düzey 3 Üzerine Bir Uygulama. Mehmet Akif Ersoy Üniversitesi İktisadi ve İdari Bilimler Fakültesi Dergisi, 5(1), 90-107.

[32] Sarı, E. B. (2017). Endüstri İşletmelerinde Ar-Ge Projelerini Öncelik Sıralamasında Entropi Ağırlıklı TOPSIS Yöntemine Dayalı Çok Kriterli Bir Analiz. International Journal of Academic Value Studies,3(11), 159-170

[33] Bakır, M., \& Akan Ş. (2018). Havaalanlarında Hizmet Kalitesinin Entropi ve TOPSIS Yöntemleri İle Değerlendirilmesi: Avrupa'nın En Yoğun Havaalanları Üzerine Bir Uygulama. Elektronik Sosyal Bilimler Dergisi, 17(66), 632-651.

[34] Demirarslan, P. Ç., Küçükönder, H., \& Kıngır, S. (2019). Entropi Tabanlı TOPSIS ve VIKOR Yaklaşımı ile Akademisyenler Üzerinde Bir Duygusal Performans Değerlendirme: Bartın Örneği. Elektronik Sosyal Bilimler Dergisi,18(69), 232-251.

[35] Freeman, J., \& Chen, T. (2015). Green supplier selection using an AHP-Entropy-TOPSIS framework. Supply Chain Management: An International Journal, 20(3), 327-340.

[36] Sun, L. Y., Miao, C. L., \& Yang, L. (2017). Ecological-Economic Efficiency Evaluation of Green Technology Iİnnovation in Strategic Emerging Industries Based on Entropy Weighted TOPSIS Method. Ecological Indicators, 73, 554-558.

[37] Xu, W., \& He, F. (2017). Entropy-TOPSIS method for selecting locations for electric vehicle charging stations. Advances in Transportation Studies, 3.

[38] Gorgij, A. D., Wu, J., \& Moghadam, A. A. (2019). Groundwater Quality Ranking Using The İmproved Entropy TOPSIS Method: A Case Study İn Azarshahr Plain Aquifer, East Azerbaijan, Iran. Human And Ecological Risk Assessment: An International Journal, 25(1-2), 176-190.

[39] Wang, Y; Wen, Z. \& HuifangLi (2020). Symbiotic Technology Assessment in İron And Steel İndustry Based on Entropy TOPSIS method .Journal of Cleaner Production, 260, 1-13.

[40] Zhang, H., Gu, C. L., Gu, L. W., \& Zhang, Y. (2011). The Evaluation of Tourism Destination Competitiveness by TOPSIS \& Information Entropy-A Case in The Yangtze River Delta of China. Tourism Management, 32(2), 443-451.

[41] Özdağoğlu, A., Yakut, E., \& Bahar, S. (2017). Machine Selection In A Dairy Product Company with Entropy and SAW Methods Integration. Dokuz Eylül Üniversitesi Iktisadi İdari Bilimler Fakültesi Dergisi,32(1), 341-359.

[42] Koca, G., Ekinci, F., \& Şimşek, M. (2019). Vergi gelirleri bakımından OECD ülkelerinin performansının bütünleşik entropi-ARAS yöntemi ile değerlendirilmesi. Elektronik Sosyal Bilimler Dergisi, 18(70), 964985. 


\begin{tabular}{|c|c|c|}
\hline & $\begin{array}{l}\text { BŞEÜ Fen Bilimleri Dergisi } \\
7(2), 714-729,2020\end{array}$ & $\begin{array}{r}\text { BSEU Journal of Science } \\
\text { DOI: } 10.35193 / \text { bseufbd.726608 }\end{array}$ \\
\hline & & 58-7575 (http://dergipark.gov.tr/bseufbd) \\
\hline
\end{tabular}

[43] Hwang, C. L., \&Yoon, K. (1981).Multiple attribute decision making methods and application. New York: Springer-Verlag 